\title{
Simulation of Arrhythmogenic Effect of Rogue RyRs in Failing Heart by Using a Coupled Model
}

\author{
Luyao Lu, ${ }^{1}$ Ling Xia, ${ }^{2}$ and Xiuwei $\mathrm{Zhu}^{1}$ \\ ${ }^{1}$ Department of Biomedical Engineering, Wenzhou Medical College, Wenzhou 325035, China \\ ${ }^{2}$ Department of Biomedical Engineering, Zhejiang University, Hangzhou 310027, China
}

Correspondence should be addressed to Ling Xia, xialing@zju.edu.cn

Received 21 June 2012; Accepted 22 August 2012

Academic Editor: Feng Liu

Copyright ( $) 2012$ Luyao Lu et al. This is an open access article distributed under the Creative Commons Attribution License, which permits unrestricted use, distribution, and reproduction in any medium, provided the original work is properly cited.

\begin{abstract}
Cardiac cells with heart failure are usually characterized by impairment of $\mathrm{Ca}^{2+}$ handling with smaller SR $\mathrm{Ca}^{2+}$ store and high risk of triggered activities. In this study, we developed a coupled model by integrating the spatiotemporal $\mathrm{Ca}^{2+}$ reaction-diffusion system into the cellular electrophysiological model. With the coupled model, the subcellular $\mathrm{Ca}^{2+}$ dynamics and global cellular electrophysiology could be simultaneously traced. The proposed coupled model was then applied to study the effects of rogue RyRs on $\mathrm{Ca}^{2+}$ cycling and membrane potential in failing heart. The simulation results suggested that, in the presence of rogue RyRs, $\mathrm{Ca}^{2+}$ dynamics is unstable and $\mathrm{Ca}^{2+}$ waves are prone to be initiated spontaneously. These release events would elevate the membrane potential substantially which might induce delayed afterdepolarizations or triggered action potentials. Moreover, the variation of membrane potential depolarization is indicated to be dependent on the distribution density of rogue RyR channels. This study provides a new possible arrhythmogenic mechanism for heart failure from subcellular to cellular level.
\end{abstract}

\section{Introduction}

Calcium is considered to be the key ion in mediating the process of cardiac excitation-contraction coupling (EC coupling). Since the discovery of $\mathrm{Ca}^{2+}$ sparks in 1993 [1], $\mathrm{Ca}^{2+}$ sparks have been widely accepted to be the stereotyped elementary $\mathrm{Ca}^{2+}$ release events in the intact myocyte. Sparks arise via clusters of ryanodine receptors (RyRs) localized in the junctional SR (jSR) which is in close apposition to transverse tubules (TTs) [2]. In a diastolic myocyte, spontaneous $\mathrm{Ca}^{2+}$ sparks occur randomly at very low frequency, even in the absence of $\mathrm{Ca}^{2+}$ influx. During a single muscle twitch, $\mathrm{Ca}^{2+}$ influx via sarcolemmal Ltype $\mathrm{Ca}^{2+}$ channels will trigger synchronously occurrence of thousands of sparks, summation of which in space and time causes a global steep rise of $\mathrm{Ca}^{2+}$ concentration named $\mathrm{Ca}^{2+}$ transient. However under some pathological conditions, successive recruitment of $\mathrm{Ca}^{2+}$ sparks tends to evolve into $\mathrm{Ca}^{2+}$ waves propagating across the myocytes which might trigger ventricular arrhythmias [3].

With the improvement of optical methods and innovative techniques, microscopic $\mathrm{Ca}^{2+}$ signals at the subcellular level have been extensively investigated and characterized. In addition to $\mathrm{Ca}^{2+}$ sparks via clustered RyRs, nonspark $\mathrm{Ca}^{2+}$ release events, named Ca quarks, activated by low-intensity photolysis of $\mathrm{Ca}^{2+}$-caged compounds [4] or by inward $\mathrm{Na}^{+}$ current, $I_{\mathrm{Na}}$ [5], could elicit spatially homogeneous but small $\mathrm{Ca}^{2+}$ transient. These quarks are likely to be mediated via one or a few RyR channels called rogue RyRs [6]. Differing from RyR clusters that underly sparks, rogue RyRs are thought to be uncoupled with each other and behave in ways more like the characteristic of single RyR channels [7]. Although detection of these small rogue RyR channels is difficult by conventional instruments, some researchers have suggested that, besides sparks, the nonspark pathway via rogue RyRs explains a part of SR $\mathrm{Ca}^{2+}$ leak $[8,9]$. Quantitatively, with the optical superresolution technique, Baddeley et al. have indicated that there are greater numbers of rogue RyR groups than large RyR clusters [10]. An experimental study that $\mathrm{Ca}^{2+}$ waves are inhibited without affecting $\mathrm{Ca}^{2+}$ sparks by ruthenium red suggests a nonspark producing RyR channels which are important to propagation of $\mathrm{Ca}^{2+}$ wave [11]. Direct visualization of small local release events has been made possible by recent technical innovations. Brochet et al. claimed that they have directly visualized quark-like or "quarky" $\mathrm{Ca}^{2+}$ release events which might depend on the 
opening of rogue RyRs (or small cluster of RyRs) in rabbit ventricular myocytes [12].

SR $\mathrm{Ca}^{2+}$ leak consists of two components: RyRdependent leak and RyR-independent leak [8]. The former is thought to be comprised of spark-mediated leak (visible leak) and non-spark-mediated leak (invisible leak). Elevated SR $\mathrm{Ca}^{2+}$ leak would contribute to delayed afterdepolarizations (DADs) and consequently arrhythmia in heart failure (HF) [13]. Besides spark-mediated leak, additional $\mathrm{Ca}^{2+}$ leak via rogue RyRs may be an important factor in disturbing $\mathrm{Ca}^{2+}$ dynamics and triggering $\mathrm{Ca}^{2+}$ waves $[11,14]$. However, how do these abnormal $\mathrm{Ca}^{2+}$ release events affect cellular electrophysiological properties? The precise relationships between property of rogue RyRs and $\mathrm{Ca}^{2+}$ handling as well as cellular electrophysiology in failing heart are not completely clear.

In this paper, we developed a coupled mathematical model including $\mathrm{Ca}^{2+}$ cycling processes from subcellular to cellular level and electrophysiology of the ventricular myocyte. The proposed coupled model was then applied to study the effects of $\mathrm{Ca}^{2+}$ release via rogue RyRs on subcellular spatiotemporal $\mathrm{Ca}^{2+}$ cycling and on the possible membrane potential changes in failing heart.

\section{Methods}

Subcellular $\mathrm{Ca}^{2+}$ release events and cellular $\mathrm{Ca}^{2+}$ cycling as well as corresponding membrane potential were simulated synchronously by a coupled model. The model consists of two parts: a two-dimensional (2D) spatial $\mathrm{Ca}^{2+}$ reactiondiffusion model and an electrophysiological model of the ventricular myocyte.

2.1. A Subcellular $\mathrm{Ca}^{2+}$ Reaction-Diffusion Model. The shape of the cardiac myocyte in the model is represented as a circular cylinder $100 \mu \mathrm{m}$ in length and $10 \mu \mathrm{m}$ in radius. However, because of quasi-isotropic diffusion of $\mathrm{Ca}^{2+}$ on the transverse section [15], a 2D model was used in our simulation work (Figure 1), where $x$ axis denotes the cell's longitudinal direction and $y$ axis is along the $Z$-line. It could still describe most of the key properties of $\mathrm{Ca}^{2+}$ waves, but needs much less computation work than a 3D model. The 2D spatiotemporal $\mathrm{Ca}^{2+}$ reaction-diffusion model is described based on a reaction-diffusion system proposed by Izu et al. [16]. Figure 1 shows the subcellular structural representation of RyRs network. The $x$-axis denotes the cell's longitudinal direction and the $y$-axis is along the $Z$-line. The blue dots represent RyR clusters which account for $\mathrm{Ca}^{2+}$ sparks. The small red dots are the rogue RyR channels which raise $\mathrm{Ca}^{2+}$ quarks. Rogue RyRs are distributed in a stochastic manner. $N_{\text {rogue }}$ is referred to the distributing density of rogue RyRs with the unit of rogue $\mathrm{RyR} / \mu \mathrm{m}^{2}$.

The free $\mathrm{Ca}^{2+}$ concentration $\left[\mathrm{Ca}^{2+}\right]_{i}$ in the reactiondiffusion is described by a differential equation as follows:

$$
\begin{aligned}
\frac{\partial\left[\mathrm{Ca}^{2+}\right]_{i}}{\partial t}= & D_{x} \frac{\partial^{2}\left[\mathrm{Ca}^{2+}\right]_{i}}{\partial x^{2}}+D_{y} \frac{\partial^{2}\left[\mathrm{Ca}^{2+}\right]_{i}}{\partial y^{2}}+J_{\text {dye }} \\
& +J_{\text {buffers }}+J_{\text {pump }}+J_{\text {leak }}+J_{\text {sub-rel }},
\end{aligned}
$$

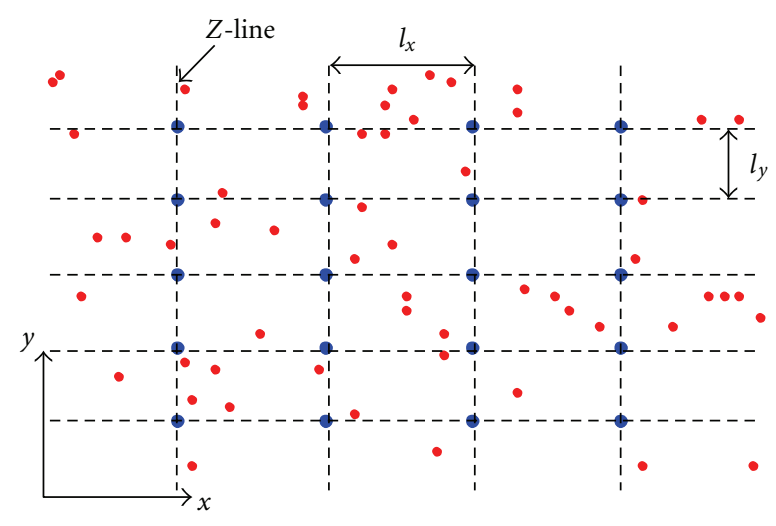

FIGURE 1: Geometry of RyRs distribution. The blue dots represent $\mathrm{Ca}^{2+}$ release units consisting of clusters of RyRs. $l_{x}=2.0 \mu \mathrm{m}$ and $l_{y}=1.0 \mu \mathrm{m}$. The small red dots are rogue RyRs which scatter over the plane randomly. In this figure, $N_{\text {rogue }}$ is equivalent to 1.0 rogue $\mathrm{RyR} / \mu \mathrm{m}^{2}$.

where $D_{x}$ and $D_{y}$ are the diffusion coefficients; $J_{\text {dye }}$ and $J_{\text {buffers }}$ are due to fluorescent indicator dye and endogenous $\mathrm{Ca}^{2+}$ buffer, respectively; $J_{\text {pump }}$ is pumping rate of $\mathrm{SR} \mathrm{Ca}^{2+}$ ATPase; $J_{\text {leak }}$ is defined as a RyR-independent leak flux which is small and invisible and persists in the presence of RyR inhibition [8]; $J_{\text {sub-rel }}$ is summation of $\mathrm{Ca}^{2+}$ release fluxes in the 2D subcellular model which consists of two types of Ca flows as follows:

$$
\begin{gathered}
J_{\text {sub-rel }}=\sum_{i, j} J_{\text {cluster }}\left(x_{i}, y_{j}\right)+\sum_{m, n} J_{\text {rogue }}\left(x_{m}, y_{n}\right), \\
J_{\text {cluster }}\left(x_{i}, y_{j}\right)=V_{\text {cluster }}\left(\left[\mathrm{Ca}^{2+}\right]_{\mathrm{SR}}-\left[\mathrm{Ca}^{2+}\right]_{i,\left(x_{i}, y_{j}\right)}\right),
\end{gathered}
$$

where $J_{\text {cluster }}\left(x_{i}, y_{j}\right)$ is $\mathrm{Ca}^{2+}$ release flux via a cluster of RyRs located on $\left(x_{i}, y_{j}\right), V_{\text {cluster }}$ is maximal $J_{\text {cluster }}$ conductance equivalent to $1.97 \times 10^{-8} \mathrm{~ms}^{-1}$, and $J_{\text {rogue }}\left(x_{m}, y_{n}\right)$ is $\mathrm{Ca}^{2+}$ release flux via a rogue RyR channel located on $\left(x_{m}, y_{n}\right)$, equivalent to $3.3166 \times 10^{-9} \mathrm{pmol} / \mathrm{ms}$.

Firings of the two types of RyR channels are considered to be stochastic processes and treated by the Monte Carlo simulation in our work. To evaluate the effects of SR luminal $\mathrm{Ca}^{2+}$ concentration $\left(\left[\mathrm{Ca}^{2+}\right]_{\mathrm{SR}}\right)$ on $\mathrm{SR} \mathrm{Ca}^{2+}$ release, we integrate a new parameter $k_{\text {CaSR }}$ into the probability of firing of $\mathrm{Ca}^{2+}$ sparks or quarks $\left(P_{j}, j=\right.$ cluster for RyR clusters, and $j=$ rogue for rogue RyRs) as follows:

$$
\begin{aligned}
& k_{\mathrm{CaSR}}=\frac{k_{\max }}{1+\left(D_{\mathrm{SR}} /\left[\mathrm{Ca}^{2+}\right]_{\mathrm{SR}}\right)^{n_{\mathrm{SR}}},} \\
& P_{j}=\frac{P_{\max }}{1+\left(K_{m j} /\left[\mathrm{Ca}^{2+}\right]_{i}\right)^{n_{j}}} k_{\mathrm{CaSR}},
\end{aligned}
$$

where $k_{\max }=2.0$, the Hill coefficient $n_{\mathrm{SR}}=4.5, P_{\max }=$ $0.3 /$ event $/ \mathrm{ms}, n_{\text {cluster }}=1.6$, and $n_{\text {rogue }}=1.0$ for the less coupled gating of rogue RyRs than RyR clusters. $D_{\mathrm{SR}}$ is luminal $\mathrm{Ca}^{2+}$ sensitivity parameter of $\mathrm{Ca}^{2+}$ release events, and $K_{m j}$ is cytoplasmic $\mathrm{Ca}^{2+}$ sensitivity parameter of RyR clusters or rogue RyR channels. In our simulation work, 
$K_{m \text { rogue }}$ was always set to be of the same value as $K_{m c l u s t e r}$; thus $K_{m}$ was used to represent the value of $K_{m c l u s t e r}$ and $K_{m \text { rogue }}$.

In this study, the simulation of subcellular $\mathrm{Ca}^{2+}$ handling was performed on the longitudinal section of a cardiac myocyte with the size of $100 \mu \mathrm{m} \times 20 \mu \mathrm{m}$ along the cellular longitudinal direction ( $x$-axis) and $Z$-line ( $y$-axis), respectively. The number of RyR clusters was $49 \times 19$ along $x$ and $y$ axes, respectively, and the total number of rogue RyRs was $N_{\text {rogue }} \times 2000 \mu \mathrm{m}^{2}$. The diffusion partial differential equation was approximated by the finite difference method (FDM) with a time-step size of $0.01 \mathrm{~ms}$ and a mesh size of $0.1 \mu \mathrm{m}$.

Because of the stochasticity of opening of RyR clusters and rogue RyRs, the properties of $\mathrm{Ca}^{2+}$ signalling were described by statistical results by carrying out repeated Monte Carlo simulations. All averaged data were expressed as mean \pm SEM. One-way analysis of variance (ANOVA) was used for comparison and $P<0.05$ was taken to indicate statistical significance.

2.2. A Cellular Electrophysiological Model. The electrophysiological behavior of a myocardial cell is modelled based on a cardiac action potential model proposed by Ten Tusscher and Panfilov [17]. The voltage across the cell membrane can be described with the following differential equation:

$$
\begin{aligned}
\frac{d V_{m}}{d t}= & -\frac{1}{C_{m}}\left(I_{\mathrm{Na}}+I_{\mathrm{CaL}}+I_{\mathrm{to}}+I_{\mathrm{Kr}}+I_{\mathrm{Ks}}+I_{\mathrm{K} 1}+I_{\mathrm{NaK}}\right. \\
& \left.+I_{\mathrm{NaCa}}+I_{\mathrm{pCa}}+I_{\mathrm{pK}}+I_{\mathrm{bCa}}+I_{\mathrm{bNa}}+I_{\mathrm{stim}}\right)
\end{aligned}
$$

where $C_{m}$ is the membrane capacitance, $I_{\text {stim }}$ is a stimulus current, and $I_{x}$ denotes all kinds of ionic currents across the sarcolemma.

However, different from the $\mathrm{Ca}^{2+}$ dynamical system by Ten Tusscher et al., global SR $\mathrm{Ca}^{2+}$ release current $J_{\text {rel }}$ at the cellular level is calculated by the summation of local $\mathrm{Ca}^{2+}$ release fluxes in the $2 \mathrm{D}$ subcellular model:

$$
\begin{aligned}
J_{\text {rel }} & =k_{\text {rel }} J_{\text {sub-rel }} \\
& =k_{\text {rel }}\left(\sum_{i, j} J_{\text {cluster }}\left(x_{i}, y_{j}\right)+\sum_{m, n} J_{\text {rogue }}\left(x_{m}, y_{n}\right)\right),
\end{aligned}
$$

where $k_{\text {rel }}$ is a constant multiplier equivalent to 22.25 in our coupled model.

2.3. Heart Failure Model. Changes of $\mathrm{Ca}^{2+}$ cycling as well as other ionic currents have been observed in failing heart; thus we modified the parameters of our coupled model to mimic abnormal $\mathrm{Ca}^{2+}$ dynamics and electrophysiological properties in heart failure from subcellular to cellular levels.

\subsection{1. $\mathrm{Ca}^{2+}$ Handling}

(a) SR $\mathrm{Ca}^{2+}$ Release Channels. In HF, RyR channels would become unstable due to phosphorylation of protein kinase A (PKA) [18] or $\mathrm{Ca}^{2+} /$ calmodulin-dependent-protein-kinaseI- (CaMKI-) induced hyperphosphorylation [19] and be oversensitive to cytoplasmic $\mathrm{Ca}^{2+}$ and SR luminal $\mathrm{Ca}^{2+}[20]$.
In our simulation study, $K_{m}$ was set to be $7.5 \mu \mathrm{M}$ and $D_{\mathrm{SR}}$ was $2.5 \mathrm{mM}$ under the condition of heart failure, while $15 \mu \mathrm{M}$ and $3.25 \mathrm{mM}$, respectively, under control condition.

(b) SR $\mathrm{Ca}^{2+}$ Pump. Pumping activity of SR $\mathrm{Ca}^{2+}$ ATPase in failing heart is reduced as shown in experimental studies [21]. A $45 \%$ reduction in $J_{\text {pump }}$ of a failing myocyte is incorporated into our HF model.

(c) SR $\mathrm{Ca}^{2+}$ Leak. Spontaneous openings of RyR clusters and rogue RyRs at diastole are the main contributors to SR $\mathrm{Ca}^{2+}$ leak as the form of $\mathrm{Ca}^{2+}$ sparks and quarks. Because of instability of RyR channels, RyR-mediated $\mathrm{Ca}^{2+}$ leak from $\mathrm{SR}$ increased in the resting HF myocyte. However, RyRindependent leak was unaltered in our HF model.

\subsubsection{Ionic Current across the Sarcolemma}

(a) Inward Rectifier Potassium Current: $I_{K 1}$. In heart failure, $I_{\mathrm{K} 1}$ was shown to be reduced in many studies [22, 23]. In our HF model the current density of $I_{\mathrm{K} 1}$ was assumed to decrease by $20 \%$.

(b) Slowly Activated Delayed Rectifier Potassium Current: $I_{K s}$. $I_{\mathrm{Ks}}$ is the slowly activated component of delayed rectifier potassium current. In the failing canine hearts $I_{\mathrm{Ks}}$ has been shown to be downregulated by nearly a half [24]. Therefore, maximal $I_{\mathrm{Ks}}$ conduction was changed to $50 \%$ of the value used in nonfailing myocytes.

(c) Transient Outward Potassium Current: $I_{\text {to }}$. According to an experimental result, the current density of $I_{\text {to }}$ in $\mathrm{HF}$ declined to $64 \%$ of the value in control cardiac cells [25], so that in our simulations $I_{\text {to }}$ was reduced to $64 \%$ in failing myocytes.

(d) Fast $\mathrm{Na}$ Current: $I_{\mathrm{Na}}$. It has been reported that the peak density of $I_{\mathrm{Na}}$ decreased significantly in heart failure [26]. Therefore, the maximal $I_{\mathrm{Na}}$ conductance $G_{\mathrm{Na}}$ was set to be $8.902 \mathrm{nS} / \mathrm{pF}$ in the failing myocytes, while equivalent to $14.838 \mathrm{nS} / \mathrm{pF}$ in the nonfailing myocytes.

(e) Na-Ca Changer Current: $I_{\mathrm{NaCa}}$. The activity and/or gene expression of $\mathrm{Na} / \mathrm{Ca}$ changer was found to be increased obviously in many experiments $[27,28]$. Thus we upregulated $I_{\mathrm{NaCa}}$ by $65 \%$ in the failing myocytes.

(f) Na-K Pump Current: $I_{N a K}$. As shown in the experimental study, the concentration of $\mathrm{Na} / \mathrm{K}$ ATPase in the failing heart was reduced by $42 \%$ [29], so that reduction of $I_{\mathrm{NaK}}$ by the same proportion was incorporated in our HF model.

(g) Ca Background Current: $I_{b C a}$. Inward $I_{b C a}$ was considered to balance $\mathrm{Ca}^{2+}$ extrusion via $\mathrm{Na} / \mathrm{Ca}$ exchanger and sarcolemmal $\mathrm{Ca}^{2+}$ pump at resting potential. In our HF model the conductance of $I_{\mathrm{bCa}}$ was increased due to the increase of $I_{\mathrm{NaCa}}$. 
TABLE 1: Parameters in nonfailing versus failing myocyte models.

\begin{tabular}{|c|c|c|c|}
\hline Parameters & Definition & Nonfailing & Failing \\
\hline$V_{\max }$ & Maximal SR $\mathrm{Ca}^{2+}$ pumping rate & $0.006375 \mathrm{mM} / \mathrm{ms}$ & $0.0035 \mathrm{mM} / \mathrm{ms}$ \\
\hline$G_{\mathrm{Ks}}$ & Maximal $I_{\mathrm{Ks}}$ conductance & $0.392 \mathrm{nS} / \mathrm{pF}$ & $0.196 \mathrm{nS} / \mathrm{pF}$ \\
\hline$G_{\mathrm{K} 1}$ & Maximal $I_{\mathrm{K} 1}$ conductance & $5.405 \mathrm{nS} / \mathrm{pF}$ & $4.324 \mathrm{nS} / \mathrm{pF}$ \\
\hline$G_{\text {to }}$ & Maximal $I_{\text {to }}$ conductance & $0.294 \mathrm{nS} / \mathrm{pF}$ & $0.185 \mathrm{nS} / \mathrm{pF}$ \\
\hline$G_{\mathrm{Na}}$ & Maximal $I_{\mathrm{Na}}$ conductance & $14.838 \mathrm{nS} / \mathrm{pF}$ & $8.902 \mathrm{nS} / \mathrm{pF}$ \\
\hline$P_{\mathrm{NaK}}$ & Maximal $I_{\mathrm{NaK}}$ & $2.724 \mathrm{pA} / \mathrm{pF}$ & $1.57 \mathrm{pA} / \mathrm{pF}$ \\
\hline$G_{\mathrm{bCa}}$ & Maximal $I_{\mathrm{bCa}}$ conductance & $0.000592 \mathrm{nS} / \mathrm{pF}$ & $0.0009045 \mathrm{nS} / \mathrm{pF}$ \\
\hline$k_{\mathrm{NaCa}}$ & Maximal $I_{\mathrm{NaCa}}$ & $1000 \mathrm{pA} / \mathrm{pF}$ & $1650 \mathrm{pA} / \mathrm{pF}$ \\
\hline$K_{m}$ & $\mathrm{Ca}^{2+}$ sensitivity parameters of RyR clusters or rogue RyR when they take the same value & $15 \mu \mathrm{M}$ & $7.5 \mu \mathrm{M}$ \\
\hline$D_{\mathrm{SR}}$ & luminal $\mathrm{Ca}^{2+}$ sensitivity parameter of $\mathrm{Ca}^{2+}$ release events & $3.25 \mathrm{mM}$ & $2.5 \mathrm{mM}$ \\
\hline
\end{tabular}

The different values of parameters in nonfailing and failing myocyte models are shown in Table 1.

\section{Results}

3.1. $\mathrm{Ca}^{2+}$ Cycling and $V_{m}$ in HF. With the proposed coupled model, firstly we simulated the action potential and calcium cycling by applying a stimulus with a frequency of $1 \mathrm{~Hz}$, duration of $1 \mathrm{~ms}$, and an amplitude of $7 \mathrm{pA}$. Figure 2 shows the simulation results of membrane potential, cytoplasmic $\mathrm{Ca}^{2+}$ concentration, $\mathrm{Ca}^{2+}$ concentration in SR lumina, and the $\mathrm{Na}^{+} / \mathrm{Ca}^{2+}$ exchanger current after 10th stimulus. While blue curves in Figure 2 are obtained under the physiological conditions, red curves are under the pathological conditions, that is, heart failure. Compared with that in nonfailing myocytes, the plateau of action potential (AP) shows a larger amplitude and longer duration, causing a significant increase in AP duration ( $\sim 45 \%$ longer than in normal condition) in heart failure. Meanwhile, decrease of the maximal conductivity of $I_{\mathrm{K} 1}$ in heart failure makes the resting potential elevate $2 \sim 3 \mathrm{mV}$. However, the amplitude of AP overshot is smaller in heart failure, which is due to the reduction of fast inward current $I_{\mathrm{Na}}$. Then at the early stage of rapid repolarization, a weakened notch is observed in heart failure AP, which is caused by a decrease of $I_{\text {to }}$. Moreover, the prolonged plateau is mainly due to decease of maximal conductivity of $I_{\mathrm{Ks}}$.

For the calcium handing in heart failure, it is mainly characterized by a significant impair of global $\mathrm{Ca}^{2+}$ transient and a much slower decay of calcium concentration. Moreover, the SR $\mathrm{Ca}^{2+}$ store is smaller in heart failure, that is, $\left[\mathrm{Ca}^{2+}\right]_{\mathrm{SR}}$ is $\sim 15 \%$ lower in resting cells, and the restoring rate of SR calcium is slower than that on control condition. Due to the changes of AP morphology and calcium transient curves together with increase of the activity of $\mathrm{Na} / \mathrm{Ca}$ exchanger, the curve of $I_{\mathrm{NaCa}}$ in heart failure differs significantly from that under normal condition. This can be seen in Figure 2(d); that is, in heart failure, both the inward and outward currents of $I_{\mathrm{NaCa}}$ are increased. However, it takes a longer time to reach the peak of inward current, and the amplitude of inward $I_{\mathrm{NaCa}}$ in resting stage is also larger compared with that under control conditions.
3.2. Dependence of $D A D$ on Rogue RyR. In heart failure myocytes, the RyR channels become very unstable and are more likely to open with the same values of $\left[\mathrm{Ca}^{2+}\right]_{i}$ and $\left[\mathrm{Ca}^{2+}\right]_{\mathrm{SR}}$ as those under normal conditions. However, the calcium release current through a RyR cluster decreases as the SR calcium store is partly unloaded, which is observed as reduction of amplitude and area of calcium sparks. Indeed, the simulation results by using our coupled model show that, although more spontaneous calcium sparks occur in failing myocytes, propagating $\mathrm{Ca}^{2+}$ waves are seldom found when there is no rogue RyRs on the 2D subcellular space without any stimulus. These spontaneous calcium sparks would slightly elevate global $\left[\mathrm{Ca}^{2+}\right]_{i}$ on the cellular level $(\Delta$ $\left.\left[\mathrm{Ca}^{2+}\right]_{i}=(1.16 \pm 0.06) \times 10^{-4} \mathrm{mM}, n=10\right)$ and depolarize transmembrane potential with a tiny amplitude $\left(\Delta V_{m}=\right.$ $4.21 \pm 0.23 \mathrm{mV}, n=10$ ) as shown in Figure 3(a).

However, how do $\mathrm{Ca}^{2+}$ dynamics and electrophysiological properties of a failing myocyte change in the presence of rogue RyR channels? We integrate rogue RyR channels into the 2D RyR grid and vary their distribution density $N_{\text {rogue }}$ to investigate the precise effect of rogue RyR channels on $\mathrm{Ca}^{2+}$ handling and membrane potential. When the density of rogue RyRs is relatively low, for example, $N_{\text {rogue }}=0.25$ rogue $\mathrm{RyR} / \mu \mathrm{m}^{2}$, spontaneously occurring calcium sparks are frequently observed in the subcellular region of HF myocytes during the resting state. Occasionally $\mathrm{Ca}^{2+}$ waves are formed, albeit at a small area, by recruiting several adjacent $\mathrm{Ca}^{2+}$ sparks. Those small $\mathrm{Ca}^{2+}$ waves could not propagate across the whole myocyte, but self-abort during a short time. Similar to the condition without rogue RyRs, global $\left[\mathrm{Ca}^{2+}\right]_{i}$ and membrane potential are not affected severely by those $\mathrm{Ca}^{2+}$ release events under the condition with low density of rogue RyRs as shown in Figure 3(a) $\left(\Delta\left[\mathrm{Ca}^{2+}\right]_{i}=(1.61 \pm\right.$ $\left.0.08) \times 10^{-4} \mathrm{mM}, \Delta V_{m}=5.95 \pm 0.29 \mathrm{mV}, n=10\right)$.

Amplification and increase rate of $\left[\mathrm{Ca}^{2+}\right]_{i}$ and $V_{m}$ should be two groups of principal parameters to evaluate the effects of rogue RyRs on $\mathrm{Ca}^{2+}$ dynamics and electrophysiological properties. Besides $\Delta\left[\mathrm{Ca}^{2+}\right]_{i}$ and $\Delta V_{m}$, two new parameters $T_{\text {peakCa }}$ and $T_{\text {peak } V_{m}}$ are used in our simulation. $T_{\text {peakCa }}$ represents the mean time to reach the peak of $\left[\mathrm{Ca}^{2+}\right]_{i}$ from the end of resting stage, and $T_{\text {peak } V_{m}}$ is the time to reach the peak of $V_{m}$. Increase rate of $\mathrm{Ca}^{2+}$ concentration and depolarization velocity could be estimated indirectly 


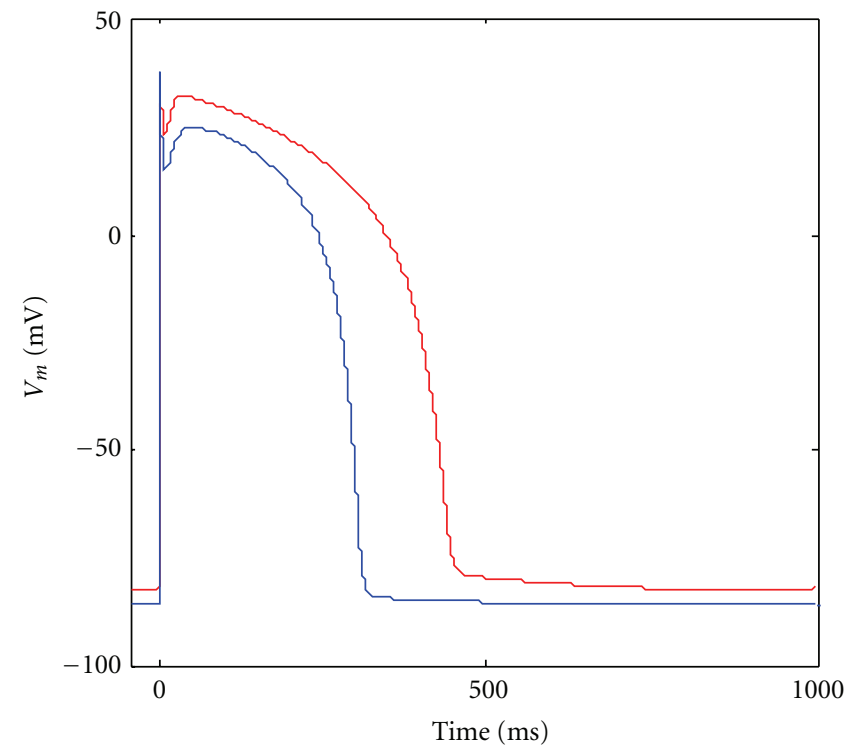

(a)

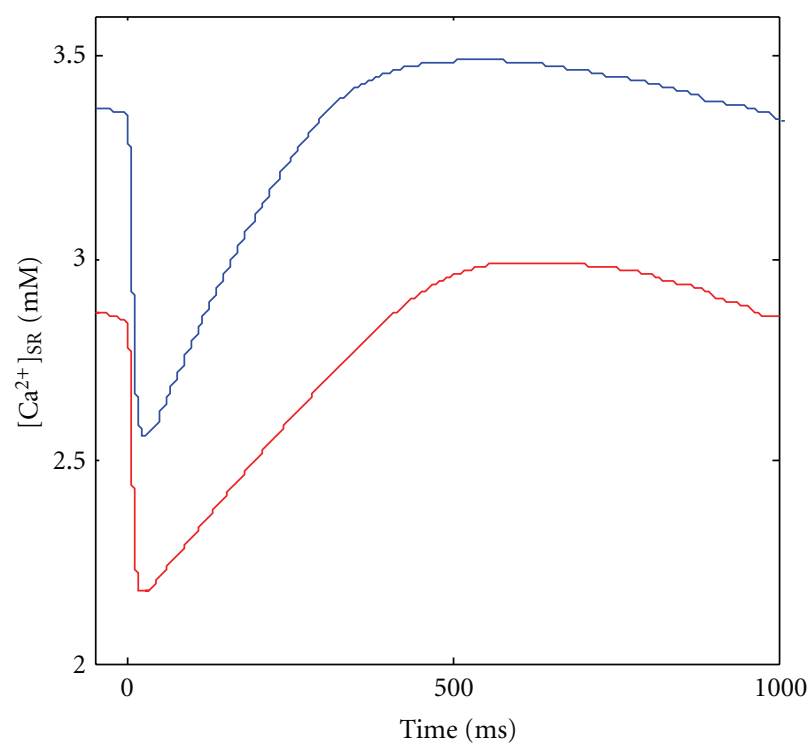

(c)

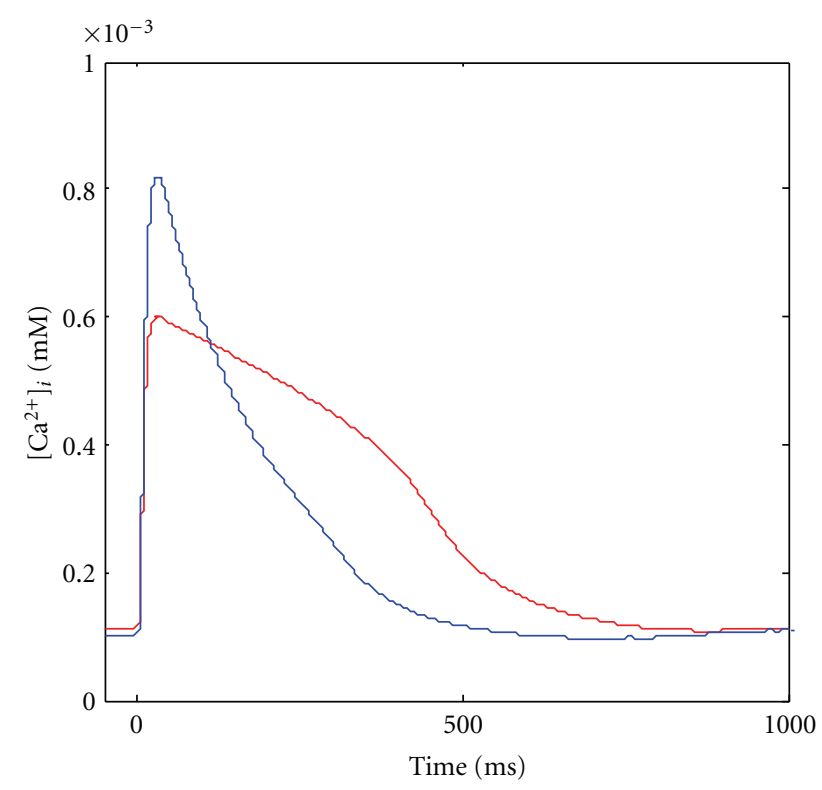

(b)

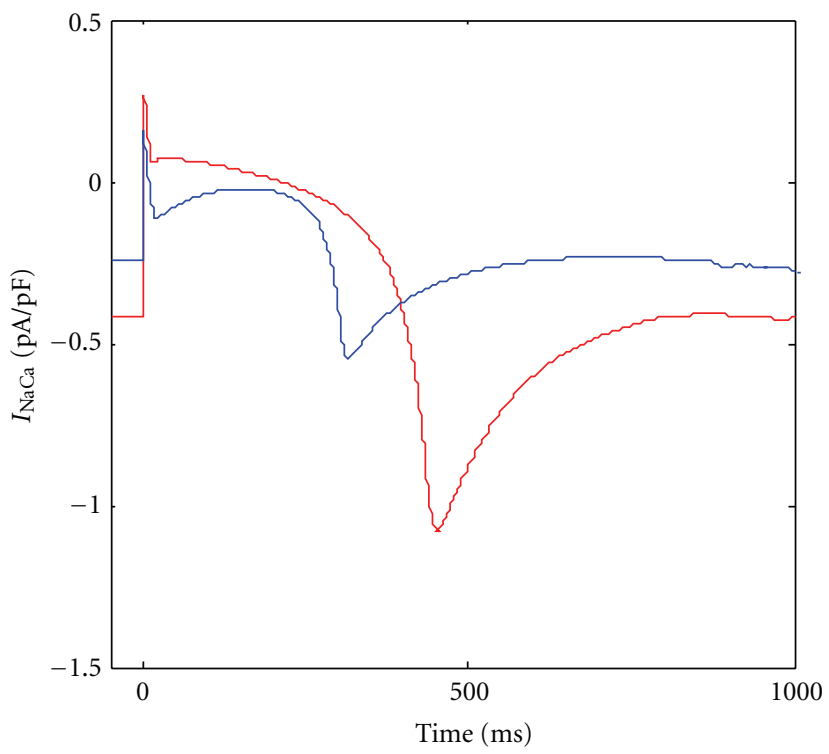

(d)

FIGURE 2: Simulation results of membrane potential $\left(V_{m}\right)(\mathrm{a})$, cytoplasmic $\mathrm{Ca}^{2+}$ concentration $\left(\left[\mathrm{Ca}^{2+}\right]_{i}\right)(\mathrm{b})$, SR luminal Ca ${ }^{2+}$ concentration $\left(\left[\mathrm{Ca}^{2+}\right]_{\mathrm{SR}}\right)(\mathrm{c})$, and $I_{\mathrm{NaCa}}(\mathrm{d})$ during a single twitch. The red curve represents the time course of those parameters in failing myocytes, while the blue curve is the time course of those parameters in control myocytes.

by the two parameters, which is shown in Figure 3(b). The simulated $T_{\text {peakCa }}$ decreases significantly when $N_{\text {rogue }}$ is upregulated from 0 to 0.25 rogue $\mathrm{RyR} / \mu \mathrm{m}^{2}\left(T_{\text {peakCa }}=418 \pm\right.$ $19.7 \mathrm{~ms}$ and $325 \pm 15.2 \mathrm{~ms}(n=10)$, resp., $n=10, P<0.05)$. However, decrease of $T_{\text {peak }} V_{m}$ is slight when $N_{\text {rogue }}$ is from 0 to 0.25 rogue $\mathrm{RyR} / \mu \mathrm{m}^{2}\left(T_{\text {peak }} V_{m}=406 \pm 38.5 \mathrm{~ms}\right.$ and $340 \pm$ 25.1 ms, resp., $n=10, P>0.05)$. In Figure 3(c) three blue curves when Time $>1000 \mathrm{~ms}$ represent repeated simulation results of $V_{m}$ without any stimulus when $N_{\text {rogue }}=0.25$ rogue $\mathrm{RyR} / \mu \mathrm{m}^{2}$. The results indicate a smooth variation without a significant peak in the membrane potential morphology.

When $N_{\text {rogue }}$ is increased to 0.5 rogue $\mathrm{RyR} / \mu \mathrm{m}^{2}$, similar to above, small spontaneous calcium waves cannot propagate in a long distance and quickly decay as well. The depolarization of membrane potential caused by calcium release events has bigger amplitude compared with that when $N_{\text {rogue }}=0.25$ rogue $\mathrm{RyR} / \mu \mathrm{m}^{2}(P<0.05)$, but is also relatively weak with an average of $7.48 \pm 0.25 \mathrm{mV}$. Again, the membrane potential morphology is smooth.

However, as $N_{\text {rogue }}$ is further increased, specifically when $N_{\text {rogue }} \geq 0.75$ rogue $\mathrm{RyR} / \mu \mathrm{m}^{2}$, large calcium waves could be initiated spontaneously in the $2 \mathrm{D}$ subcellular region. Moreover, our Monte-Carlo simulation results show that these large calcium release events cause a significant larger calcium transient at the whole cell level and subsequently depolarize the membrane potential to a larger extent when 

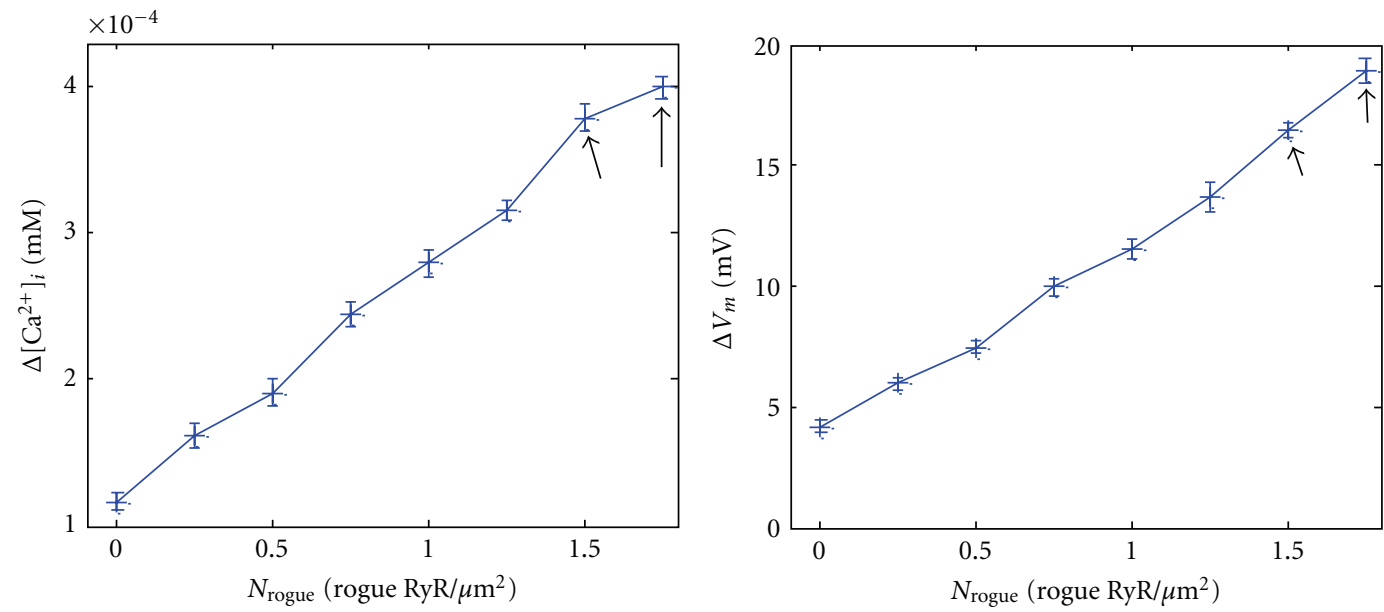

(a)
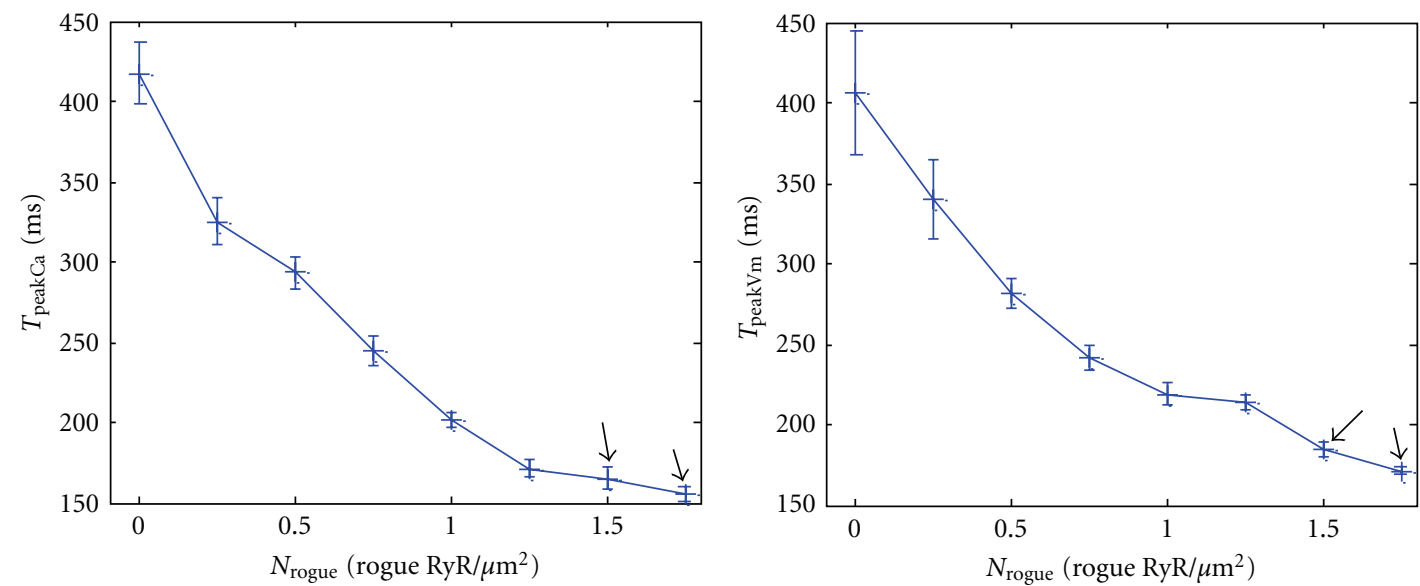

(b)

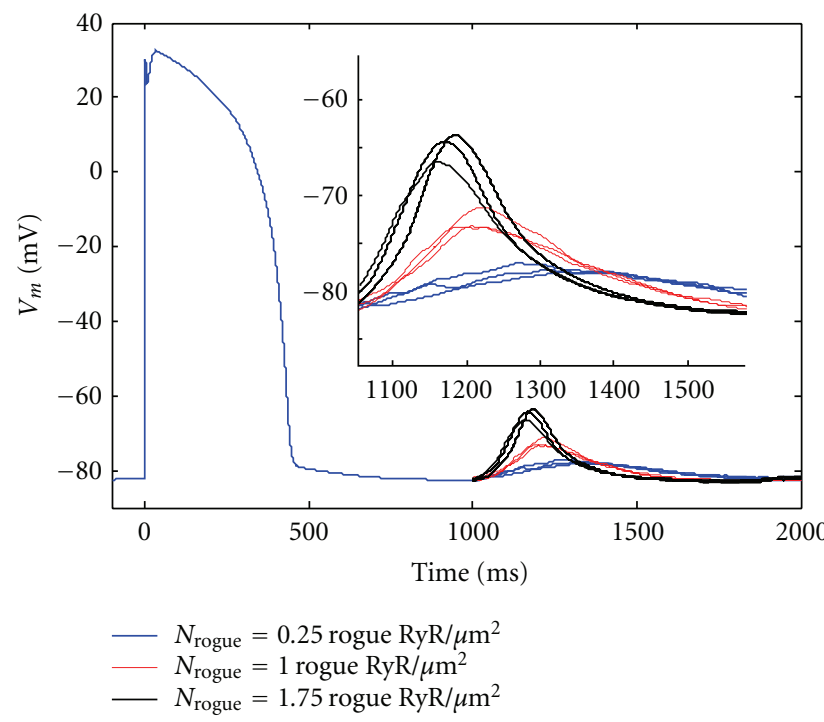

(c)

Figure 3: (a) Effects of distribution density of rogue RyRs on global change in $\left[\mathrm{Ca}^{2+}\right]_{i}\left(\Delta\left[\mathrm{Ca}^{2+}\right]_{i}\right.$, left image $)$ and depolarization of membrane potential $\left(\Delta V_{m}\right.$, right image ) without any external stimulus in heart failure. (b) Dependence of $T_{\text {peakCa }}$ and $T_{\text {peak } V_{m}}$ on $N_{\text {rogue }}$. $T_{\text {peakCa }}$ represents the time to reach the peak of global $\left[\mathrm{Ca}^{2+}\right]_{i}$ from the end of resting stage, and $T_{\text {peak }} V_{m}$ is the time to reach the peak of $V_{m}$. For each $N_{\text {rogue }}$, we simulated 10 times under the same conditions to get statistical results due to the randomness of opening of RyR channels. The values denoted by arrows in (a) and (b) are recorded when $I_{\mathrm{Na}}=0 \mathrm{pA}$. (c) Three groups of simulation results of $V_{m}$ when $N_{\text {rogue }}=0.25$, 1.0, and 1.75 rogue $\mathrm{RyR} / \mu \mathrm{m}^{2}$ (blue, red, and black curves, resp.). The inset is the enlarged view of depolarization of membrane potential during the period of $1100 \mathrm{~ms} \sim 1500 \mathrm{~ms}$. $I_{\mathrm{Na}}$ is also set to be $0 \mathrm{pA}$ when $N_{\text {rogue }}=1.75$ rogue $\mathrm{RyR} / \mu \mathrm{m}^{2}$. 

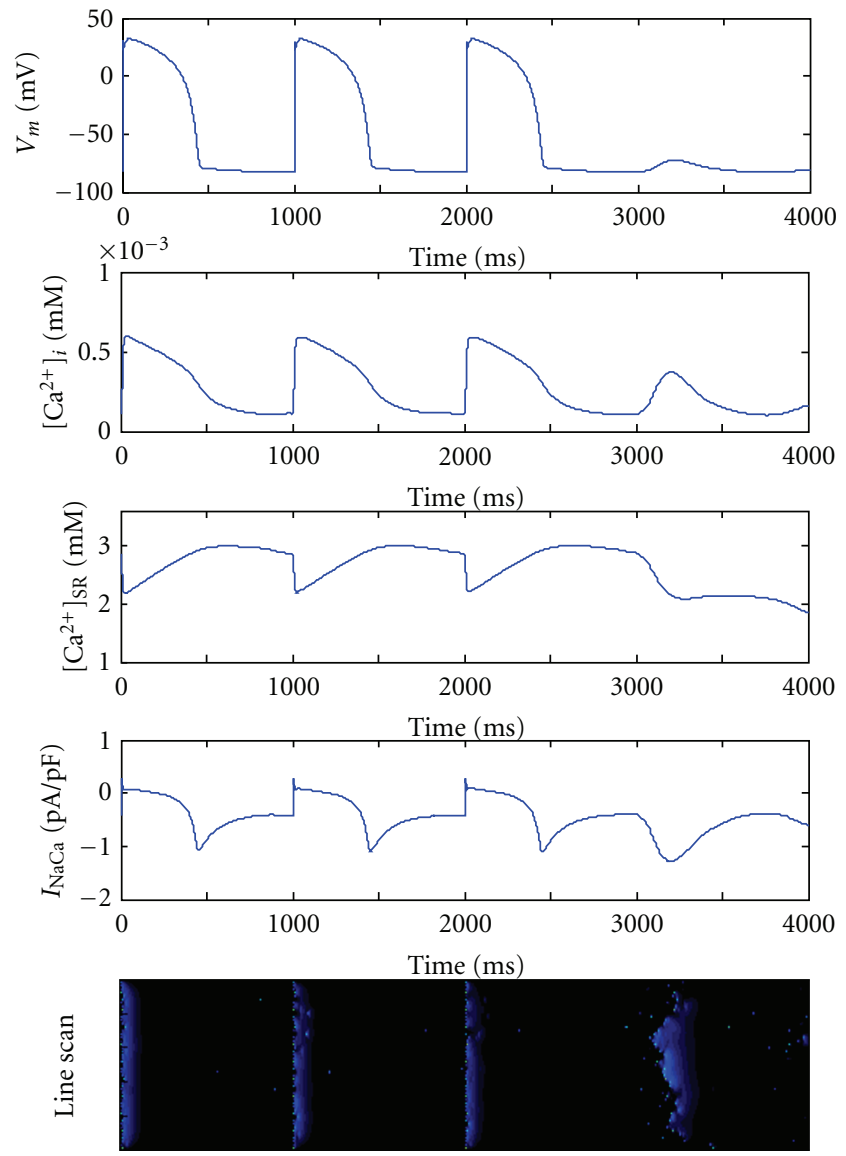

FIGURE 4: Occurrence of DAD following three action potentials in failing myocyte when $N_{\text {rogue }}=1.0$ rogue RyR $/ \mu \mathrm{m}^{2}$. Five figures from top to bottom represent membrane potential, cytoplasmic $\left[\mathrm{Ca}^{2+}\right]_{i}$, SR luminal $\left[\mathrm{Ca}^{2+}\right]_{\mathrm{SR}}, I_{\mathrm{NaCa}}$, and line-scan image along longitudinal direction of the cell, respectively, in failing ventricular myocyte.

$N_{\text {rogue }}$ is increased by a step of 0.25 rogue $\mathrm{RyR} / \mu \mathrm{m}^{2}(P<$ 0.05 ) as shown in Figure 3. Figure 4 shows typical simulation results when $N_{\text {rogue }}=1.0$ rogue $\mathrm{RyR} / \mu \mathrm{m}^{2}$. After 3 action potentials paced by the cycle length of $1000 \mathrm{~ms}$, a relatively large $\mathrm{Ca}^{2+}$ transient is observed, as well as a big inward $I_{\mathrm{NaCa}}$ and consequently a DAD without external stimulus in the heart failure myocytes. The linescan image in Figure 4 indicates the underlying microcosmic $\mathrm{Ca}^{2+}$ cycling on the subcellular level.

Besides, as $N_{\text {rogue }}$ is increased to a larger value, $\mathrm{Ca}^{2+}$ transient elicited by spontaneous $\mathrm{Ca}^{2+}$ release and the depolarization of membrane potential enlarge further $(P<$ $0.05)$, while the values of $T_{\text {peakCa }}$ and $T_{\text {peak } V_{m}}$ decrease significantly $(P<0.05)$ (as shown in Figure 3 ). All these results together suggest close relationship between rogue RyRs and DADs.

3.3. Triggered Action Potential. As demonstrated above, the spontaneous $\mathrm{Ca}^{2+}$ release from SR causes a $\mathrm{Ca}^{2+}$ transient in cytoplasm and subsequently depolarizes the membrane potential even in the resting stage without any stimulus. Furthermore, the amplitude of calcium transient and the
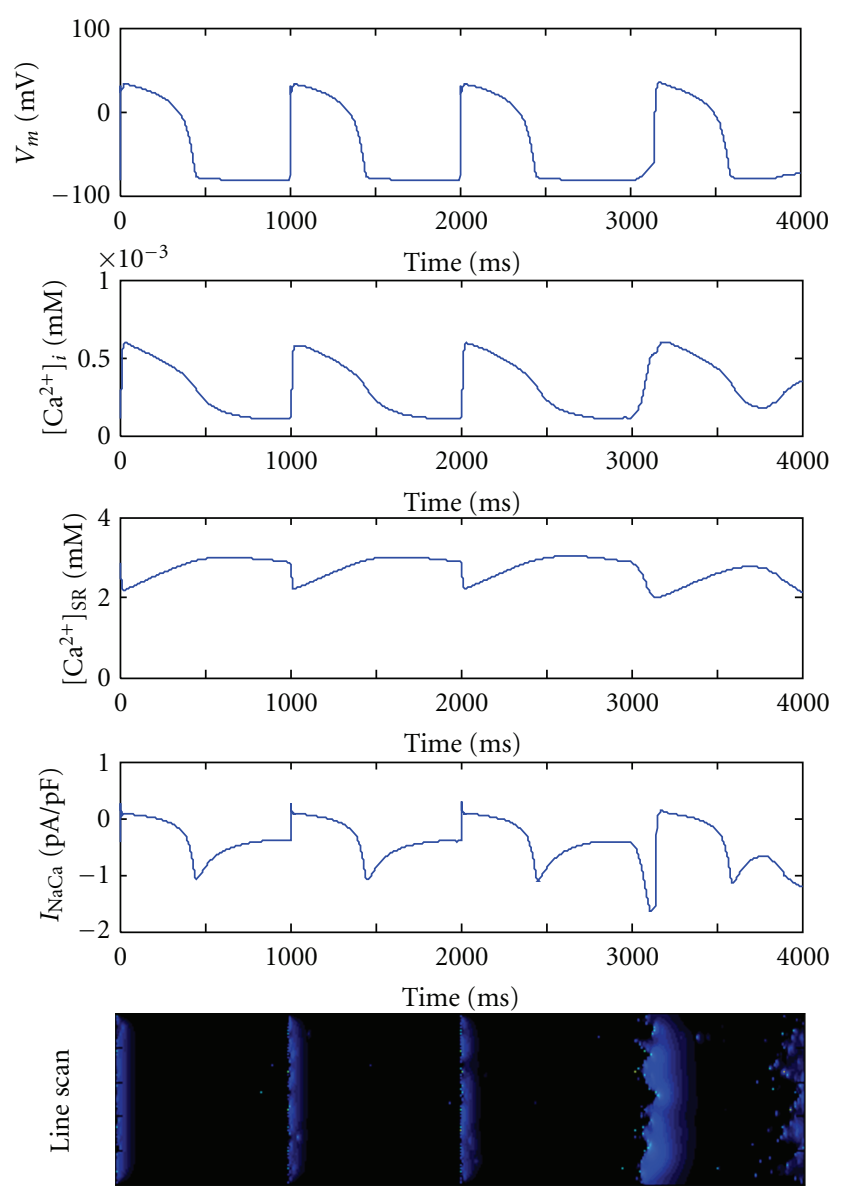

FIGURE 5: Triggered action potential in failing myocyte when $N_{\text {rogue }}$ $=1.75$ rogue RyR $/ \mu \mathrm{m}^{2}$. Five figures from top to bottom represent membrane potential, cytoplasmic $\left[\mathrm{Ca}^{2+}\right]_{i}$, SR luminal $\left[\mathrm{Ca}^{2+}\right]_{S R}$, $I_{\mathrm{NaCa}}$, and line-scan image along longitudinal direction of the myocyte, respectively, in failing ventricular cell.

degree of depolarization are positively correlated to the distribution density of rogue RyR channels. Therefore, once the density of rogue RyRs is large enough, the membrane potential may be depolarized to reach the threshold that will trigger an action potential.

Figure 5 shows the time course of simulated membrane potentials: cytoplasmic $\mathrm{Ca}^{2+}$ concentration, $\mathrm{SR} \mathrm{Ca}^{2+}$ store, the $\mathrm{Na} / \mathrm{Ca}$ exchange current, as well as the $\mathrm{Ca}^{2+}$ dynamics at subcellular level. From the line-scan image we can see that, along the cellular longitudinal direction, many spontaneous $\mathrm{Ca}^{2+}$ waves are initiated nearly at the same time. These $\mathrm{Ca}^{2+}$ waves could propagate and diffuse to finally form a large wave. These $\mathrm{Ca}^{2+}$ releases rise the $\left[\mathrm{Ca}^{2+}\right]_{i}$ quickly and drive a strong inward component of $I_{\mathrm{NaCa}}$, which causes the depolarization of the membrane potential. When the membrane potential is depolarized to reach the threshold for activation of fast $\mathrm{Na}^{+}$channel, the large $I_{\mathrm{Na}}$ is produced very fast and induces an upstroke of the membrane potential. Then, the L-type $\mathrm{Ca}^{2+}$ channels will be subsequently activated and a flux of extracellular calcium ions burst into cytoplasm via the L-type calcium channels. This inflow of $\mathrm{Ca}^{2+}$ together 
with the previously released $\mathrm{Ca}^{2+}$ from SR can activate the remaining available RyR channels and elicit an even larger $\mathrm{Ca}^{2+}$ transient in the cytoplasm. The other ionic channels at the membrane are successively opened and determine the morphology of AP together. Particularly, for the $I_{\mathrm{NaCa}}$, it switches to a weak outward current during the plateau stage, but turns to a strong inward current in the repolarization stage of AP, by which the $\mathrm{Ca}^{2+}$ is ejected to the extracellular space.

When $N_{\text {rogue }}=1.5$ rogue $\mathrm{RyR} / \mu \mathrm{m}^{2}$, triggered APs are observed in 11 simulations (totally 22 Monte Carlo simulations), that is, the probability of triggered AP is $50 \%$. Moreover, when $N_{\text {rogue }}=1.75$ rogue $\mathrm{RyR} / \mu \mathrm{m}^{2}$, triggered APs are found in 18 out of 21 Monte Carlo simulations, that is, the probability of triggered AP rises to $87.5 \%$. On the contrary, when $N_{\text {rogue }}<1.5$ rogue $\mathrm{RyR} / \mu \mathrm{m}^{2}$, no triggered AP is seen in our simulations.

To quantitatively investigate the effect of high dense rogue $\mathrm{RyRs}$ on $\mathrm{Ca}^{2+}$ handling, we also recorded the variations of $\left[\mathrm{Ca}^{2+}\right]_{i}$ and membrane potential $\left(\Delta\left[\mathrm{Ca}^{2+}\right]_{i}\right.$ and $\left.\Delta V_{m}\right)$ as well as $T_{\text {peakCa }}$ and $T_{\text {peak } V_{m}}$. However, $\Delta V_{m}$ elicited by intensive $\mathrm{Ca}^{2+}$ release events is often large enough to activate $I_{\mathrm{Na}}$. Consequently, the voltage upstroke induced by $I_{\mathrm{Na}}$ would overlap the original $\Delta V_{m}$. Then, $\Delta\left[\mathrm{Ca}^{2+}\right]_{i}$ by $\mathrm{Ca}^{2+}$ release events is also overlapped by the following inward-flowing $I_{\mathrm{CaL}}$ during a triggered AP. Under those conditions, the measurement of $\Delta\left[\mathrm{Ca}^{2+}\right]_{i}$ and $\Delta V_{m}$ as well as $T_{\text {peakCa }}$ and $T_{\text {peak } V_{m}}$ becomes very difficult. Thus, in our simulation, when $N_{\text {rogue }} \geqslant 1.5$ rogue $\mathrm{RyR} / \mu \mathrm{m}^{2}$, we set the $I_{\mathrm{Na}}$ to be zero after removing the external stimulus. By doing this, triggered AP will not be formed even when a DAD makes the membrane potential more positive than the threshold for $I_{\mathrm{Na}}$. Therefore, we can calculate these parameters easily. Actually, our simulation results are shown in Figure 3 marked by arrows, from which we can conclude that, as $N_{\text {rogue }}$ is increased from 1.5 to 1.75 rogue $\mathrm{RyR} / \mu \mathrm{m}^{2}$, the amplitude of $\left[\mathrm{Ca}^{2+}\right]_{i}$ enlarges $(P<0.05)$, whereas the time to reach the peak does not change obviously $(P>0.05)$. However, the amplitude of a DAD increases significantly $(P<0.05)$, while the time to observe the DAD decreases $(P<0.05)$.

\section{Discussion}

4.1. Mechanism of $\mathrm{Ca}$ Handling in HF. Heart failure, a syndrome caused by significant impairments in cardiac function, has become one of the biggest human killers with a poor prognosis [30]. $\mathrm{Ca}^{2+}$ handling of cardiac cells in heart failure is always characterized by reduction in the amplitude as well as by slowed decay of $\mathrm{Ca}^{2+}$ transient [31]. The primary reason for decrease in the amplitude of $\mathrm{Ca}^{2+}$ transient is the partly unloaded $\mathrm{Ca}^{2+}$ store in SR. Three factors mainly accounting for the smaller store are (1) increased $\mathrm{Ca}^{2+}$ leak in the resting myocyte, (2) decreased activity of $\mathrm{SR} \mathrm{Ca}^{2+}$ pump, and (3) increase in expression and/or activity of $\mathrm{Na}^{+}-\mathrm{Ca}^{2+}$ exchanger.

Despite the increased activity of $\mathrm{Na} / \mathrm{Ca}$ exchanger, at the early stage of $\left[\mathrm{Ca}^{2+}\right]_{i}$ decay, the net current of $\mathrm{Na} / \mathrm{Ca}$ exchanger might be outward current (i.e., $\mathrm{Ca}^{2+}$ influx) or weak inward current, due to longer AP plateau and higher plateau potential in failing myocyte. Therefore, slowed decay of $\mathrm{Ca}^{2+}$ transient is mainly due to decreased $\mathrm{SR} \mathrm{Ca}^{2+}$ pump, which removes major amount of $\mathrm{Ca}^{2+}$ at the early stage of $\left[\mathrm{Ca}^{2+}\right]_{i}$ decay. Only when the membrane potential is repolarized to a relatively negative voltage and $\left[\mathrm{Ca}^{2+}\right]_{i}$ is still high that $I_{\mathrm{NaCa}}$ turns to a strong inward current and accelerates decay of $\mathrm{Ca}^{2+}$ transient at the late stage of $\left[\mathrm{Ca}^{2+}\right]_{i}$ decay.

4.2. Arrhythmogenic Effect of Rogue RyRs. Besides pump failure, patients with severe heart failure are at high risk of sudden cardiac death generally triggered by a lethal arrhythmia $[23,32]$. DADs are thought to be the primary mechanism underlying arrhythmia in failing heart [33]. In our simulation work, although the probability of firing of RyR clusters increases in resting failing cardiocytes, the spontaneous $\mathrm{Ca}^{2+}$ sparks could not elicit enough amplitude of $\mathrm{Ca}^{2+}$ transient to induce an obvious DAD in the absent of rogue RyRs. The existence of rogue RyR channels is of importance in initiation and propagation of spontaneous $\mathrm{Ca}^{2+}$ waves in ventricular myocytes with heart failure [14].

In this work, we propose a coupled mathematic model by integrating the spatiotemporal $\mathrm{Ca}^{2+}$ reaction-diffusion system into the cellular electrophysiological model. Rogue RyR channels are then incorporated into the coupled model to simulate subcellular $\mathrm{Ca}^{2+}$ dynamics and global cellular electrophysiology simultaneously under heart failure conditions. Our simulation results show that, in the presence of rogue RyRs, $\mathrm{Ca}^{2+}$ dynamics is more unstable and $\mathrm{Ca}^{2+}$ waves are more likely to be initiated than the condition without rogue RyRs. Different from sporadic sparks in a resting myocyte without $\mathrm{Ca}^{2+}$ waves, a number of SR $\mathrm{Ca}^{2+}$ release events occur intensively during the process of spontaneous occurrence of $\mathrm{Ca}^{2+}$ waves. These release events could elevate the amplitude of $\mathrm{Ca}^{2+}$ transient effectively and thus induce $\mathrm{Ca}^{2+}$-dependent inward current (mainly via $\mathrm{Na} / \mathrm{Ca}$ exchanger) which depolarizes the sarcolemma and lends to a DAD, or a triggered AP sometimes. For a given level of $\mathrm{Ca}^{2+}$ release in failing myocytes, inward depolarizing current becomes larger due to increased activity of $\mathrm{Na} / \mathrm{Ca}$ exchanger. And increased membrane resistance owing to reduction of $I_{\mathrm{K} 1}$ enables the same inward current to produce greater depolarization. Once a DAD elevates membrane potential to the threshold for activation of $I_{\mathrm{Na}}$, a triggered AP is then formed. DADs and triggered AP are the primary triggered activities accounting for arrhythmias in heart failure.

4.3. Dependence of $V_{m}$ on Density of Rogue RyRs. Without rogue RyR channels or with low distribution density, occurrence of spontaneous $\mathrm{Ca}^{2+}$ sparks and/or quarks is independent in time and space, which is unlikely to evolve into propagating $\mathrm{Ca}^{2+}$ waves with partially unloaded SR $\mathrm{Ca}^{2+}$ store. $\left[\mathrm{Ca}^{2+}\right]_{i}$ variation elicited by these $\mathrm{Ca}^{2+}$ release events is slight. In our simulation, when $N_{\text {rogue }}=0$ or 0.25 rogue $\mathrm{RyR} / \mu \mathrm{m}^{2}$, the amplitude of membrane potential depolarization is very small, only several $\mathrm{mV}$, and the average 
$T_{\text {peak } V_{m}}$ is big and extensive with large SEM. The morphology of membrane potential is very smooth without a distinct peak, so that this type of depolarization could not be referred to a genuine $\mathrm{DAD}$.

However, as more rogue RyRs are distributed over the 2D plane, $\Delta V_{m}$ increases gradually, while the value of $T_{\text {peak } V_{m}}$ decreases but becomes more intensive. When the value of $N_{\text {rogue }}$ is elevated to 1.5 rogue $\mathrm{RyR} / \mu \mathrm{m}^{2}$ or bigger, the large membrane potential depolarization tends to evoke a triggered AP, and the probability of occurrence of triggered APs increases with the larger $N_{\text {rogue }}$. The reason is that larger number of rogue RyRs would increase the amplitude and rate of DADs by initiating more $\mathrm{Ca}^{2+}$ waves which occur more synchronously. Therefore, depolarization of $V_{m}$ is indicated to be dependent on the distribution density of rogue RyR channels.

4.4. Limitations and Further Work. Because the rogue RyR remains to be a hypothetical channel rather than a determinate concept, experimental parameters of rogue RyRs are lacked. Some assumptions were made regarding the density, distribution, and kinetic of rogue RyR channels. In our work, a constant was used to represent $\mathrm{Ca}^{2+}$ release flux via a rogue RyR channel, while $\mathrm{Ca}^{2+}$ release flux via a cluster of RyRs was dependent on global luminal $\mathrm{Ca}^{2+}$ concentration $\left(\left[\mathrm{Ca}^{2+}\right]_{\mathrm{SR}}\right)$ and local $\mathrm{Ca}^{2+}$ concentration $\left(\left[\mathrm{Ca}^{2+}\right]_{i(x i, y i)}\right)$. Besides, different $N_{\text {rogue }}$ values were used to evaluate the effect of rogue $\mathrm{RyR}$ on $\mathrm{Ca}^{2+}$ cycling and membrane potential in failing heart.

Numerous key regulatory proteins, such as protein kinase A(PKA), Calstalin, CaMKII, and phosphatase, are bound to RyR, thus forming the junctional complex. RyR channels would be regulated via different signaling pathways [34]. For example, PKA phosphorylation dissociates FKBP12.6 from the RyR and thus makes the RyR channel unstable in failing hearts [35]. These regulating processes could not be mimiced by our present model. Besides, defective $\mathrm{Ca}^{2+}$ handling also occurs in many cardiac diseases, such as myocardial infarction, atrial fibrillation, and various arrhythmogenic paradigms. The coupled model is planned to be improved, and more relevant parameters should be added to investigate the potential mechanisms of $\mathrm{Ca}^{2+}$ dynamics in various kinds of cardiac diseases.

\section{Summary}

By integrating the spatiotemporal $\mathrm{Ca}^{2+}$ reaction-diffusion model into the cellular electrophysiological model, appearance of subcellular $\mathrm{Ca}^{2+}$ release events and evolution of waves together with dynamics of ionic concentration and membrane potential on the cellular level could been monitored simultaneously. By using the coupled model we investigate the effects of rogue RyRs on $\mathrm{Ca}^{2+}$ handling from subcellular to cellular level as well as electrophysiological properties in failing heart. The simulation results suggest that rogue RyR with tiny $\mathrm{Ca}^{2+}$ release flux should be an important factor in triggering arrhythmia in failing cardiac cells. Our work suggests the importance of rogue RyRs in initiation of $\mathrm{Ca}^{2+}$ release events (especially $\mathrm{Ca}^{2+}$ waves) and consequently DADs or triggered APs. Our study indicates the arrhythmogenic effect of rogue RyRs and helps to elucidate a possible arrhythmia mechanism in failing heart.

\section{Acknowledgments}

This project is supported by the 973 National Basic Research \& Development Program (2007CB512100) and the National Natural Science Foundation of China (81171421).

\section{References}

[1] H. Cheng, W. J. Lederer, and M. B. Cannell, "Calcium sparks: elementary events underlying excitation-contraction coupling in heart muscle," Science, vol. 262, no. 5134, pp. 740-744, 1993.

[2] C. Franzini-Armstrong, F. Protasi, and V. Ramesh, "Shape, size, and distribution of $\mathrm{Ca}^{2+}$ release units and couplons in skeletal and cardiac muscles," Biophysical Journal, vol. 77, no. 3, pp. 1528-1539, 1999.

[3] E. G. Lakatta and T. Guarnieri, "Spontaneous myocardial calcium oscillations: are they linked to ventricular fibrillation?" Journal of Cardiovascular Electrophysiology, vol. 4, no. 4, pp. 473-489, 1993.

[4] P. Lipp and E. Niggli, "Submicroscopic calcium signals as fundamental events of excitation-contraction coupling in guinea-pig cardiac myocytes," Journal of Physiology, vol. 492, no. 1, pp. 31-38, 1996.

[5] P. Lipp, M. Egger, and E. Niggli, "Spatial characteristics of sarcoplasmic reticulum $\mathrm{Ca}^{2+}$ release events triggered by L-type $\mathrm{Ca}^{2+}$ current and $\mathrm{Na}^{+}$current in guinea-pig cardiac myocytes," Journal of Physiology, vol. 542, no. 2, pp. 383-393, 2002.

[6] E. A. Sobie, S. Guatimosim, L. Gómez-Viquez et al., "The $\mathrm{Ca}^{2+}$ leak paradox and "rogue ryanodine receptors": SR Ca ${ }^{2+}$ efflux theory and practice," Progress in Biophysics and Molecular Biology, vol. 90, no. 1-3, pp. 172-185, 2006.

[7] W. Xie, D. X. P. Brochet, S. Wei, X. Wang, and H. Cheng, "Deciphering ryanodine receptor array operation in cardiac myocytes," Journal of General Physiology, vol. 136, no. 2, pp. 129-133, 2010.

[8] A. V. Zima, E. Bovo, D. M. Bers, and L. A. Blatter, " $\mathrm{Ca}^{2+}$ spark-dependent and -independent sarcoplasmic reticulum $\mathrm{Ca}^{2+}$ leak in normal and failing rabbit ventricular myocytes," Journal of Physiology, vol. 588, no. 23, pp. 4743-4757, 2010.

[9] D. J. Santiago, J. W. Curran, D. M. Bers et al., "Ca sparks do not explain all ryanodine receptor-mediated SR Ca leak in mouse ventricular myocytes," Biophysical Journal, vol. 98, no. 10, pp. 2111-2120, 2010.

[10] D. Baddeley, I. D. Jayasinghe, L. Lam, S. Rossberger, M. B. Cannell, and C. Soeller, "Optical single-channel resolution imaging of the ryanodine receptor distribution in rat cardiac myocytes," Proceedings of the National Academy of Sciences of the United States of America, vol. 106, no. 52, pp. 22275-22280, 2009.

[11] N. MacQuaide, H. R. Ramay, E. A. Sobie, and G. L. Smith, "Differential sensitivity of $\mathrm{Ca}^{2+}$ wave and $\mathrm{Ca}^{2+}$ spark events to ruthenium red in isolated permeabilised rabbit cardiomyocytes," Journal of Physiology, vol. 588, no. 23, pp. 4731-4742, 2010.

[12] D. X. P. Brochet, W. Xie, D. Yang, H. Cheng, and W. J. Lederer, "Quarky calcium release in the heart," Circulation Research, vol. 108, no. 2, pp. 210-218, 2011. 
[13] T. R. Shannon, S. M. Pogwizd, and D. M. Bers, "Elevated sarcoplasmic reticulum $\mathrm{Ca}^{2+}$ leak in intact ventricular myocytes from rabbits in heart failure," Circulation Research, vol. 93, no. 7, pp. 592-594, 2003.

[14] L. Lu, L. Xia, X. Ye, and H. Cheng, "Simulation of the effect of rogue ryanodine receptors on a calcium wave in ventricular myocytes with heart failure," Physical Biology, vol. 7, no. 2, Article ID 026005, 2010.

[15] L. T. Izu, J. R. H. Mauban, C. W. Balke, and W. G. Wier, "Large currents generate cardiac $\mathrm{Ca}^{2+}$ sparks," Biophysical Journal, vol. 80, no. 1, pp. 88-102, 2001.

[16] L. T. Izu, W. G. Wier, and C. W. Balke, "Evolution of cardiac calcium waves from stochastic calcium sparks," Biophysical Journal, vol. 80, no. 1, pp. 103-120, 2001.

[17] K. H. W. J. Ten Tusscher and A. V. Panfilov, "Alternans and spiral breakup in a human ventricular tissue model," American Journal of Physiology, vol. 291, no. 3, pp. H1088-H1100, 2006.

[18] S. E. Lehnart, X. H. T. Wehrens, and A. R. Marks, "Calstabin deficiency, ryanodine receptors, and sudden cardiac death," Biochemical and Biophysical Research Communications, vol. 322, no. 4, pp. 1267-1279, 2004.

[19] X. Ai, J. W. Curran, T. R. Shannon, D. M. Bers, and S. M. Pogwizd, " $\mathrm{Ca}^{2+} /$ calmodulin-dependent protein kinase modulates cardiac ryanodine receptor phosphorylation and sarcoplasmic reticulum $\mathrm{Ca}^{2+}$ leak in heart failure," Circulation Research, vol. 97, no. 12, pp. 1314-1322, 2005.

[20] S. Nattel, A. Maguy, S. Le Bouter, and Y. H. Yeh, "Arrhythmogenic ion-channel remodeling in the heart: heart failure, myocardial infarction, and atrial fibrillation," Physiological Reviews, vol. 87, no. 2, pp. 425-456, 2007.

[21] R. H. G. Schwinger, M. Bohm, U. Schmidt et al., "Unchanged protein levels of SERCA II and phospholamban but reduced $\mathrm{Ca}^{2+}$ uptake and $\mathrm{Ca}^{2+}$-ATPase activity of cardiac sarcoplasmic reticulum from dilated cardiomyopathy patients compared with patients with nonfailing hearts," Circulation, vol. 92, no. 11, pp. 3220-3228, 1995.

[22] D. J. Beuckelmann, M. Nabauer, and E. Erdmann, "Alterations of $\mathrm{K}^{+}$currents in isolated human ventricular myocytes from patients with terminal heart failure," Circulation Research, vol. 73, no. 2, pp. 379-385, 1993.

[23] G. F. Tomaselli and D. P. Zipes, "What causes sudden death in heart failure?" Circulation Research, vol. 95, no. 8, pp. 754-763, 2004.

[24] G. R. Li, C. P. Lau, A. Ducharme, J. C. Tardif, and S. Nattel, "Transmural action potential and ionic current remodeling in ventricles of failing canine hearts," American Journal of Physiology, vol. 283, no. 3, pp. H1031-H1041, 2002.

[25] M. Näbauer, D. J. Beuckelmann, P. Überfuhr, and G. Steinbeck, "Regional differences in current density and ratedependent properties of the transient outward current in subepicardial and subendocardial myocytes of human left ventricle," Circulation, vol. 93, no. 1, pp. 168-177, 1996.

[26] C. R. Valdivia, W. W. Chu, J. Pu et al., "Increased late sodium current in myocytes from a canine heart failure model and from failing human heart," Journal of Molecular and Cellular Cardiology, vol. 38, no. 3, pp. 475-483, 2005.

[27] G. Hasenfuss, W. Schillinger, S. E. Lehnart et al., "Relationship between $\mathrm{Na}^{+}-\mathrm{Ca}^{2+}$-exchanger protein levels and diastolic function of failing human myocardium," Circulation, vol. 99, no. 5, pp. 641-648, 1999.

[28] K. R. Sipido, P. G. A. Volders, M. A. Vos, and F. Verdonck, "Altered $\mathrm{Na} / \mathrm{Ca}$ exchange activity in cardiac hypertrophy and heart failure: a new target for therapy?" Cardiovascular Research, vol. 53, no. 4, pp. 782-805, 2002.
[29] O. I. Shamraj, I. L. Grupp, G. Grupp et al., "Characterisation of $\mathrm{Na} / \mathrm{K}-\mathrm{ATPase}$, its isoforms, and the inotropic response to ouabain in isolated failing human hearts," Cardiovascular Research, vol. 27, no. 12, pp. 2229-2237, 1993.

[30] D. W. Baker, D. Einstadter, C. Thomas, and R. D. Cebul, "Mortality trends for 23,505 medicare patients hospitalized with heart failure in Northeast Ohio, 1991 to 1997," American Heart Journal, vol. 146, no. 2, pp. 258-264, 2003.

[31] Z. Kubalova, D. Terentyev, S. Viatchenko-Karpinski et al., "Abnormal intrastore calcium signaling in chronic heart failure," Proceedings of the National Academy of Sciences of the United States of America, vol. 102, no. 39, pp. 14104-14109, 2005.

[32] D. M. Roden, "A surprising new arrhythmia mechanism in heart failure," Circulation Research, vol. 93, no. 7, pp. 589-591, 2003.

[33] S. M. Pogwizd and D. M. Bers, "Cellular basis of triggered arrhythmias in heart failure," Trends in Cardiovascular Medicine, vol. 14, no. 2, pp. 61-66, 2004.

[34] M. Yano, Y. Ikeda, and M. Matsuzaki, "Altered intracellular $\mathrm{Ca}^{2+}$ handling in heart failure," Journal of Clinical Investigation, vol. 115, no. 3, pp. 556-564, 2005.

[35] S. O. Marx, S. Reiken, Y. Hisamatsu et al., "PKA phosphorylation dissociates FKBP12.6 from the calcium release channel (ryanodine receptor): defective regulation in failing hearts," Cell, vol. 101, no. 4, pp. 365-376, 2000. 


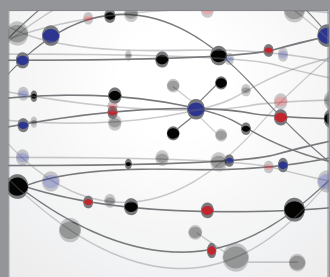

The Scientific World Journal
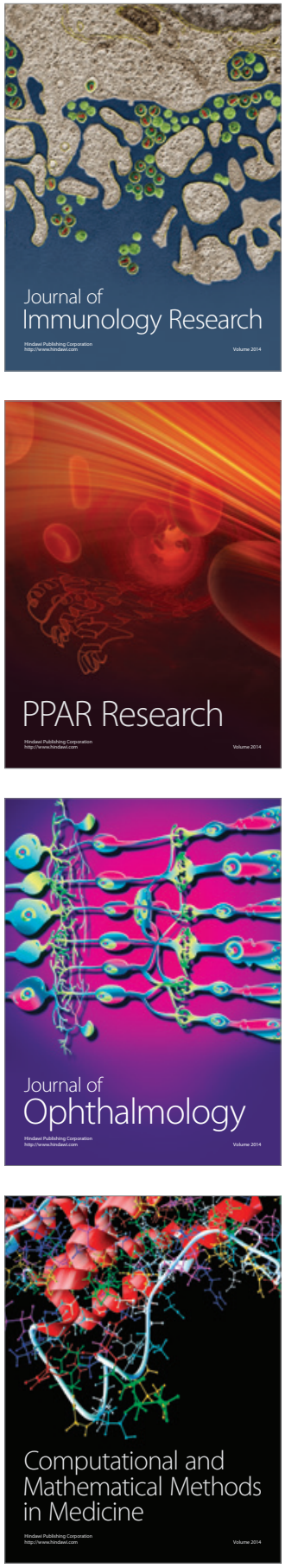

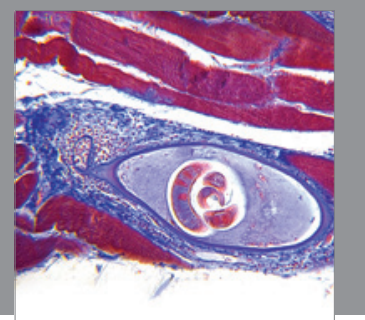

Gastroenterology

Research and Practice
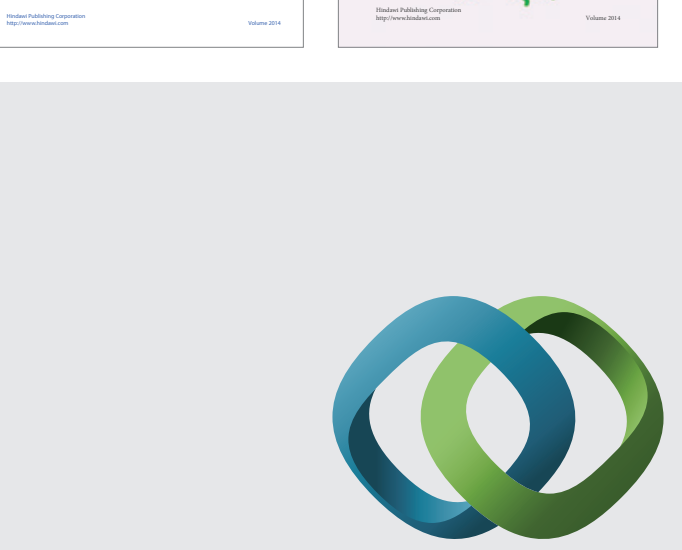

\section{Hindawi}

Submit your manuscripts at

http://www.hindawi.com
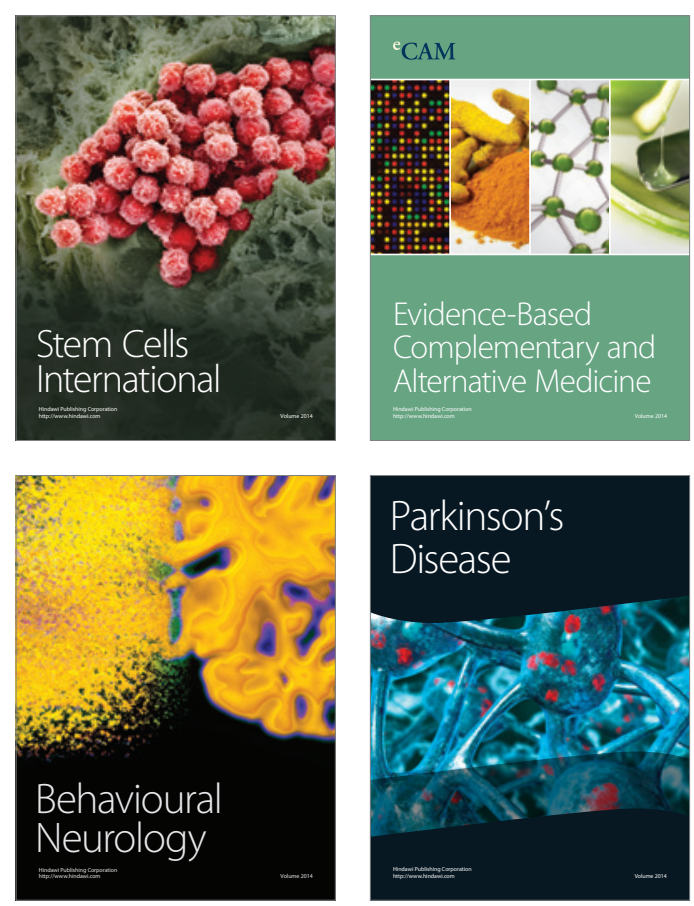

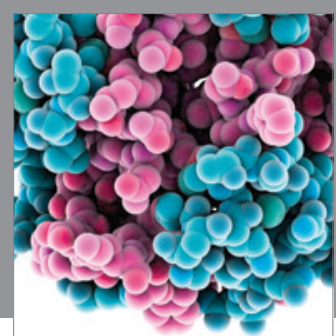

Journal of
Diabetes Research

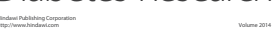

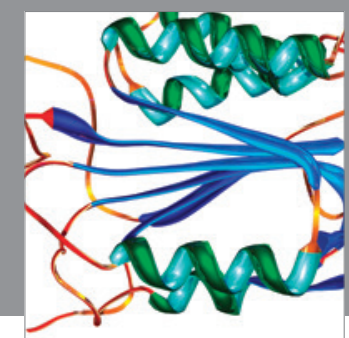

Disease Markers
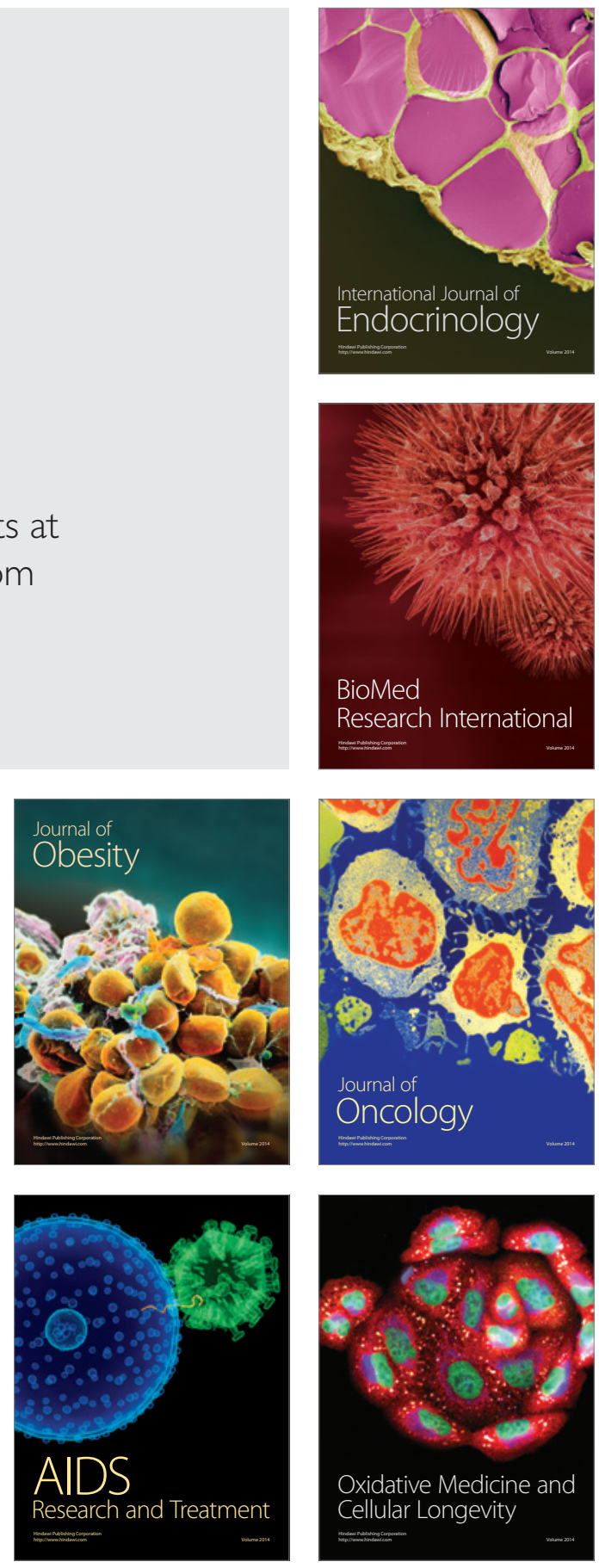